\title{
An unusual clinical presentation of labial fusion in post pubertal period
}

\section{Kiran Pandey, Kaustubh Srivastava, Snehlata Singh*, Pavika Lal}

Department of Obstetrics and Gynecology, GSVM Medical College, Kanpur, Uttar Pradesh, India

Received: 01 November 2017

Accepted: 20 January 2018

\section{*Correspondence:}

Dr. Snehlata Singh,

E-mail: dr.snehlata.17@gmail.com

Copyright: (C) the author(s), publisher and licensee Medip Academy. This is an open-access article distributed under the terms of the Creative Commons Attribution Non-Commercial License, which permits unrestricted non-commercial use, distribution, and reproduction in any medium, provided the original work is properly cited.

\begin{abstract}
Labial fusion is sealing of labia minora in midline, also known as labial adhesion or labial agglutination or synechia vulvae. This condition is common in pre-pubertal females usually asymptomatic when oestrogen levels are low and commonly resolves spontaneously post-puberty if unresolved medical treatment includes use of estrogen cream or betamethasone cream application, very rarely surgical treatment required, if not responding to medical treatment due to dense adhesions. This case report is unusual as it has presented in a post-pubertal female requiring surgical management.
\end{abstract}

Keywords: Labial adhesion, Labial agglutination, Labial fusion, Synechia vulvae, Surgical excision

\section{INTRODUCTION}

Labial fusion occurs when both the lips of labia minora around the vaginal introitus become fused together or covered with a fleshy membrane. The membrane usually completely seals the vaginal opening, leaving a very small opening at the front through which urine or menstrual blood passes. It is also known as labial agglutination or labial adhesion. Labial fusion affects 2$5 \%$ of babies and young girls, most commonly seen between 1-2 years of age. ${ }^{1}$

\section{CASE REPORT}

An eighteen-year-old female presented to gynaecological OPD with complain of passing urine and menstrual blood with a single small opening for 4 years after her attainment of menarche at 14 years of age. Her menstrual cycle was regular, normal in amount and duration with occasional mild dysmenorrhea. On examination she has well developed secondary sexual characters. There was no history of sexual abuse, trauma and allergic rash over external genitalia in past. Her general and systemic examination was normal. On per abdominal examination- normal. On local examination of genitals, labia majora was normal and labia minora was densely and firmly fused in midline. Urethral opening was not visualized, and Perineum was normal, no scar mark on the external genitalia visible except a small circular opening visualized near fourchette (Figure 1). On per rectal examination, uterus and cervix felt with evidence of no vaginal ballooning.

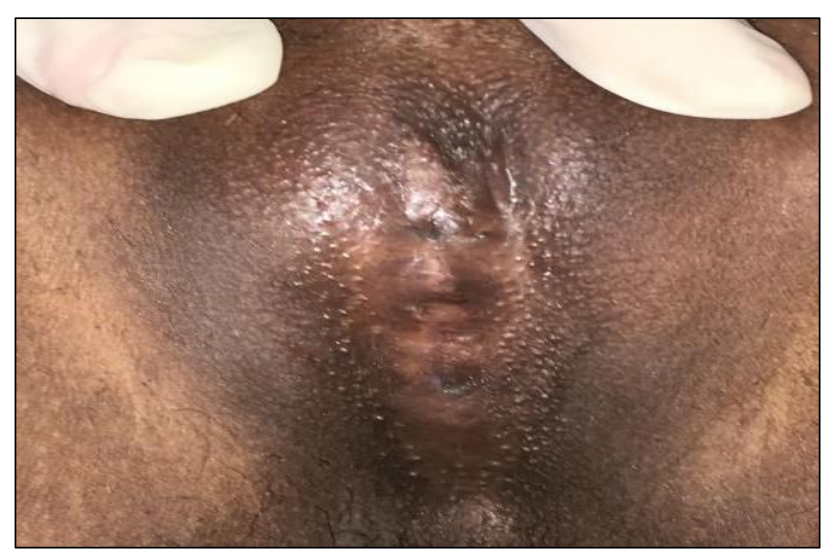

Figure 1: Small circular opening near fourchette. 
Ultrasound showed uterus anteverted and normal size, bilateral ovaries were normal. All routine investigations needed for surgery were done and noted normal. So, the case was diagnosed as labial fusion and treated surgically.

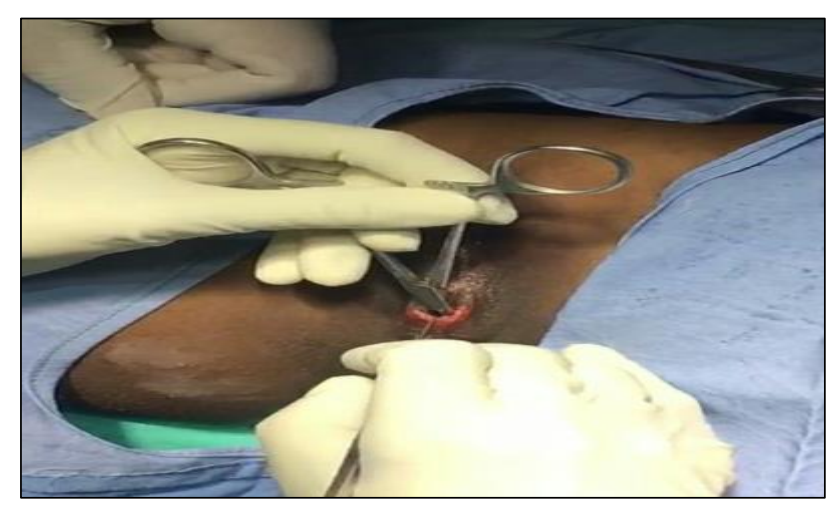

Figure 2: Layer by layer dissection.

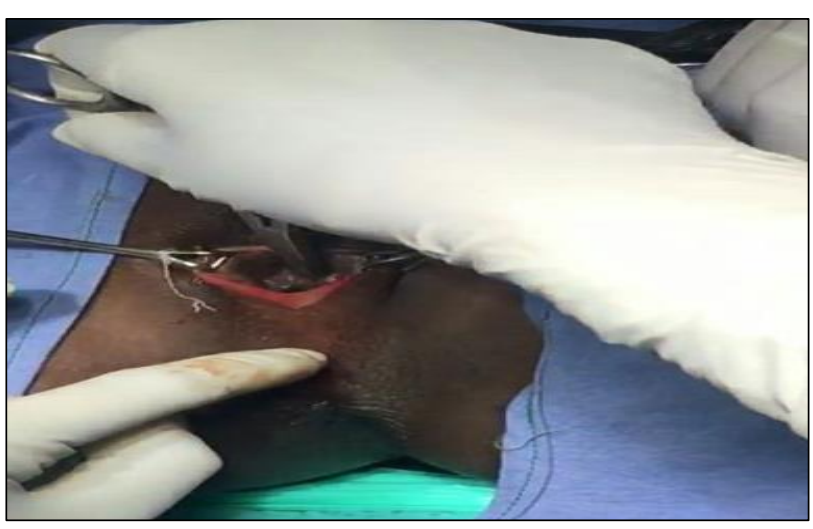

Figure 3: Dissection for visualization of urethra.

A decision for labia minora reconstruction was taken. The fused tissue from introital opening dissected layer by layer and opened anteriorly (Figure 2). Anterior wall of vagina was seen. Normal rugosity was maintained. Sharp and blunt dissection was carried upwards to visualize the urethral opening (Figure 3). The urethral meatal opening was seen $1 \mathrm{~cm}$ below the clitoris. A catheter was passed through it. The final appearance of vagina inside which healthy cervix is visualized with a catheter in urethra. Post-operative course was uneventful. An antibiotic ointment and estrogen cream for local application was given. Catheter was removed on day 3. Patient passed urine uneventfully.

\section{DISCUSSION}

The external female genitalia consist of labia majora and labia minora with the two labia minora lie on either side of vagina and urethra. In labial adhesion the labia minora get adhered to each other. It usually noticed by parents in toddler age group as a fleshy membrane joining the labia minora of vulva, completely concealing the vaginal opening and leaving only a very small opening at the front through which she passes urine. It gives an impression of absent vagina. In severe cases, there may be inability to pass urine. The exact cause is unknown, but it is suspected that labial adhesions are cause by irritation of the external genitalia cause may be feces, urine, strong perfumed soaps vulvovaginitis, aopic dermatitis labial injuries, sexual abuse. Low estrogen levels are also thought to contribute to development of such adhesions.

The condition usually resolves during puberty because the effect of estrogen changes the cells that line the genitals. It is generally asymptomatic but can also present with complaint of urine pooling in vagina on voiding followed by leakage from the vagina on standing after voiding or changes in the direction of urine stream. In about $20 \%$ of girls, asymptomatic bacteriuria develops and up to $40 \%$ experience symptomatic urinary tract infections. the medical treatment of labial adhesions for young girls include application of conjugated estrogen or estradiol vaginal cream $(0.01 \%)$ to the adhesions $(1-2$ times) daily for several weeks until resolution of adhesion. ${ }^{3}$ While there are no available randomized controlled trials, the success rate of such creams is reported in the literature to be close to $90 \%$ with minimal recurrence. ${ }^{4-6}$ An alternative line of treatment is topical $0.05 \%$ betamethasone cream of twice daily betamethasone for 4-6 weeks have showed promising results. $^{7}$ Adhesions if dense or not responding to medical treatment may require surgical management. Which includes division by gentle traction or running a sound along the fusion line. ${ }^{8}$ Once the labial adhesions are separated, emollient such as antibiotic ointment applied several times a day to prevent adhesion formation. The recurrence rate of labial adhesions after surgery is 11$14 \% .{ }^{9}$ Such adhesions especially post-surgical are denser and less likely to resolve with conservative line of management, necessitating the use of amniotic membrane, rotational skin flaps with varying rate of success.

\section{CONCLUSION}

Labial fusion rarely present in post pubertal period with urinary symptoms and sometimes requiring expertise of surgical management to avoid its recurrence.

\section{Funding: No funding sources \\ Conflict of interest: None declared \\ Ethical approval: Not required}

\section{REFERENCES}

1. Leung AK, Robson WL, Tay-Uyboco J. The incidence of labial fusion in children. J Paediatr Child Health. 1993;29(3):235-6.

2. McCann J, Voris J, Simon M. Labial adhesions and posterior fourchette injuries in childhood sexual abuse. Am J Dis Child. 1988;142(6):659-63. 
3. Goldman RD. Child health update: estrogen cream for labial adhesion in girls. Can Fam Physician. 2013;59(1):37-8.

4. Capraro VJ, Greenberg H. Adhesions of the labia minora. A study of 50 patients. Obstet Gynecol. 1972;39(1):65-9.

5. Aribarg A. Topical oestrogen therapy for labial adhesions in children. $\mathrm{Br} \mathrm{J}$ Obstet Gynaecol. 1975;82(5):424-5.

6. Khanam W, Chogtu L, Mir Z, Shawl F. Adhesion of the labia minora: a study of 75 cases. Obstet Gynecol Surv. 1978;33(5):364-5.

7. Myers JB, Sorensen CM, Wisner BP, Furness PD, Passamaneck M, Koyle MA. Betamethasone cream for the treatment of pre-pubertal labial adhesions. J Pediatr Adolesc Gynecol. 2006;19(6):407-11.

8. Michala SM. Fused labia: a paediatric approach. Obstet Gynaecol. 2009;11:261-4.

9. Soyer T. Topical estrogen therapy in labial adhesions in children: therapeutic or prophylactic? Journal Pediatr Adolescent Gynecol. 2007;20(4):241-4.

Cite this article as: Pandey K, Srivastava K, Singh S, Lal P. An unusual clinical presentation of labial fusion in post pubertal period. Int $\mathbf{J}$ Reprod Contracept Obstet Gynecol 2018;7:1233-5. 